\title{
Liver function in protein-energy malnutrition measured by cinnamic acid tolerance and benzoic acid tolerance: effect of carnitine supplementation
}

\author{
By DEBORAH A. AHERN AND MADELEINE E. MITCHELL* \\ Department of Food Science and Human Nutrition, Washington State University, \\ Pullman, Washington 99164-2032, USA
}

(Received 5 July 1988 - Accepted 14 October 1988)

1. Rats fed on a protein-depleted diet for 8 weeks were repleted for 5 weeks on high-protein (HP), highprotein $+20 \mathrm{~g} \mathrm{DL-carnitine} / \mathrm{kg}(\mathrm{HP}+\mathrm{C})$, or low-protein $+20 \mathrm{~g} \mathrm{DL}$-carnitine $/ \mathrm{kg}(\mathrm{LP}+\mathrm{C})$ diets. At 4 and 8 weeks of depletion, and 1 and 5 weeks of repletion, rats from each treatment group were given a benzoic acid tolerance test (BATT) or a cinnamic acid tolerance test (CATT) as a measure of liver function.

2. BATT and CATT measured the molar percentage of a test dose $(1 \mathrm{mmol} / \mathrm{kg}$ body-weight $)$ of benzoic acid or cinnamic acid excreted in the urine as hippuric acid within $24 \mathrm{~h}$. Liver weight, liver lipid levels, and carnitine concentration in plasma and liver were also measured following liver-function testing.

3. BATT and CATT were severely impaired in protein-depleted rats, but returned rapidly to control levels following protein refeeding. Correlations of BATT and CATT with liver lipid concentration were high $(r-0.49$ and -0.62 respectively), and both tests show promise as clinical tests for liver function in protein-energy malnutrition.

4. Carnitine supplementation was required to return liver carnitine concentration of protein-depleted rats to control levels during repletion, but was not associated with accelerated reduction in liver fat concentration in protein-repleted rats.

Fatty infiltration of the liver has long been recognized as a hallmark of kwashiorkor (Williams, 1935). Although not always fatal, severe fatty liver correlates with a high mortality rate in children with protein-energy malnutrition (PEM) (Waterlow et al. 1960; McLean, 1962; Garrow \& Pyke, 1967). The cause of fatty liver of PEM is poorly understood, and specific treatment to increase the rate of removal of this fat during recovery has not been developed (Waterlow, 1975).

Impaired lipid oxidation due to carnitine deficiency may play a role in fatty liver. A derivative of the amino acids lysine and methionine, carnitine is needed for normal oxidation of fatty acids in mitochondria, and may become deficient with diets that produce PEM. Carnitine supplementation may be a useful adjunct to the usual treatment for PEM, both to correct carnitine deficiencies (Broquist \& Borum, 1981) and to serve as a pharmacological aid to hasten fat removal (Sengers et al. 1980). Research efforts to demonstrate effective treatments for fatty liver, however, are hampered by the absence of liver function tests appropriate for children with PEM.

The present study evaluates two liver function tests (the benzoic acid tolerance test (BATT) and the cinnamic acid tolerance test (CATT)) in weanling rats at different stages of protein depletion and repletion, and assesses the impact of carnitine supplementation on recovery from fatty liver in experimental PEM.

\section{METHODS}

Male weanling Sprague-Dawley rats were fed on stock diet until they attained a weight of $100-130 \mathrm{~g}$ at the initiation of the study. They were housed individually in suspended stainless-steel mesh cages in a temperature-controlled environment with $12 \mathrm{~h}$ light-12 h dark cycles. 
Table 1. Composition of high-protein and protein-depleted-low-protein experimental diets $(\mathrm{g} / \mathrm{kg})$

\begin{tabular}{lcc}
\hline Component & High-protein & $\begin{array}{c}\text { Protein-depleted- } \\
\text { low-protein }\end{array}$ \\
\hline Dextrin* & 435 & 555 \\
Sucrose $\dagger$ & 210 & 265 \\
Lactalbumin* & 180 & 5 \\
AIN-76 mineral mix $\ddagger$ & 50 & 50 \\
AIN-76 vitamin mix§ & 5 & 5 \\
Choline chloride $\|$ & 10 & 10 \\
Vegetable oil & 100 & 100 \\
Cellulose** & 10 & 10 \\
Total & 1000 & 1000 \\
\hline
\end{tabular}

* US Biochemicals.

$\uparrow \mathrm{C} \&$ W Sugar.

¥ ICN Nutritional Biochemicals. At $50 \mathrm{~g} / \mathrm{kg}$ diet AIN-76 mineral mix provided (mg/kg diet): calcium 7430.0, phosphorus $5710 \cdot 0$, sodium $1460 \cdot 0$, potassium $5140 \cdot 0$, magnesium $710 \cdot 0$, manganese $77 \cdot 0$, iron $50 \cdot 0$, copper $8 \cdot 6$, zinc $43 \cdot 0$, iodine $0 \cdot 3$, selenium $0 \cdot 14$, chromium $2 \cdot 9$, chloride $2230 \cdot 0$, sulphate $1430 \cdot 0$.

§ ICN Nutritional Biochemicals. At $5 \mathrm{~g} / \mathrm{kg}$ diet AIN-76 vitamin mix provided (mg $/ \mathrm{kg}$ diet): thiamin hydrochloride $3 \cdot 0$, riboflavin $3 \cdot 0$, pyridoxine hydrochloride $3 \cdot 5$, nicotinic acid $15 \cdot 0$, calcium pantothenate $8 \cdot 0$, folic acid $1 \cdot 0$, biotin $0 \cdot 1$, cyanocobalamin $5 \cdot 0 \mu \mathrm{g}$, retinyl palmitate 8 , cholecalciferol $1 \cdot 25$, DL-tocopherol acetate 100 , menaquinone $25 \mu \mathrm{g}$.

\| Sigma Chemical Company.

ๆ Wesson Vegetable Oil.

** Alphacel; ICN Nutritional Biochemicals.

The study was designed in two stages, a depletion stage ( 8 weeks) and a repletion stage ( 5 weeks). For the depletion stage, rats were randomly assigned to either a protein-depleted $\operatorname{diet}(5 \mathrm{~g}$ lactalbumin $/ \mathrm{kg}$ ) or a control diet (a stock open-formula cereal-based diet). The protein-depleted diet (Table 1) has been shown to produce symptoms of kwashiorkor, including oedema, in rats within 2 months (Edozien, 1968; Anthony \& Edozien, 1975).

Protein-depleted rats were repleted on one of three diets: $180 \mathrm{~g}$ lactalbumin $/ \mathrm{kg}$ (highprotein; HP) diet; $180 \mathrm{~g}$ lactalbumin plus $20 \mathrm{~g}$ DL-carnitine $/ \mathrm{kg}(\mathrm{HP}+\mathrm{C}) \mathrm{diet}$; or $5 \mathrm{~g}$ lactalbumin $/ \mathrm{kg}$ (low-protein) plus $20 \mathrm{~g}$ DL-carnitine $(\mathrm{LP}+\mathrm{C})$ diet. Control rats continued on a stock diet during the repletion stage. This diet was provided in pelleted form and had the following composition $(\mathrm{g} / \mathrm{kg}$ diet): maize 525 , wheat 112 , soya bean 200 , lucerne (Medicago sativa) De-Hi 50, brewer's yeast 50, dehydrated whey 25 , dicalcium phosphate 25 , limestone 5 , iodized sodium chloride 5 , trace mineral mix with cobalt 1 , poultry developer vitamin premix 2.5 .

At four time-periods in the study ( 4 weeks and 8 weeks of the depletion stage, and 1 week and 5 weeks of the repletion stage) rats from each group were randomly chosen for liver function tests using either BATT or CATT. These tests measure the molar percentage of a benzoic acid or cinnamic acid dose excreted as hippuric acid in $24 \mathrm{~h}$. A total of 137 rats were given tolerance tests, with a minimum of five rats from each treatment group given each test. Test substances were administered intraperitoneally in a $0.2 \mathrm{M}$-neutral saline solution ( 9 g sodium chloride/1) containing a molar equivalent of glycine at a volume calculated to deliver $1 \mathrm{mmol}$ test substance/ $\mathrm{kg}$ body-weight. Urine was collected for $24 \mathrm{~h}$ and freezedried. At the time of analysis, urine samples were reconstituted to a volume estimated to contain approximately $1 \mathrm{mg}$ hippuric acid $/ \mathrm{ml}$. Hippuric acid in duplicate urine samples was determined by thin-layer chromatography (Teuchy \& Van Sumere, 1969). 
Immediately following the tolerance tests, rats were killed by asphyxiation with carbon dioxide. Plasma samples and weighed livers were frozen for subsequent analysis. Liver lipid was determined gravimetrically (Harding et al. 1967), liver total carnitine according to Pace et al. (1978), and plasma total carnitine according to McGarry \& Foster (1976) in at least five rats from each treatment group. Both carnitine assays are specific for the L-carnitine isomer.

One-way analysis of variance was used to analyse response variables by treatment group. Log transformations were computed for values for liver lipid and liver carnitine concentration before statistical analysis. Where significant differences were found, means were compared using Student-Newman-Keul's multiple-comparisons test. Correlation coefficients between liver function tests and lipid variables were also determined (Steel \& Torrie, 1975).

\section{RESULTS}

Body-weight and food intake

Body-weight fell markedly for rats fed on a low-protein diet during the 8-week depletion period. Total loss averaged 45 (SE 12) g. Almost $60 \%$ of the loss occurred in the first 2 weeks on the depletion diet. Control rats gained an average of 250 (SE 70) g during the same period. Weights of protein-depleted rats rose when adequate dietary protein was reintroduced during the repletion period. Repletion weight gain for the group fed on diet $\mathrm{HP}+\mathrm{C}$, however, was significantly less $(P<0.025)$ than for the group fed on the HP repletion diet. Overall, average weight gain was approximately $13 \mathrm{~g}$ less in the former group over the 5-week period.

When carnitine alone was added, in the $\mathrm{LP}+\mathrm{C}$ repletion diet, protein-depleted rats continued the decline in weight established during the depletion stage. Food intake averaged 5 (SE 1) g/d over the course of the 5-week repletion period, so that total DLcarnitine intake for $35 \mathrm{~d}$ was $21 \mathrm{mmol}$. Because of their greater mean daily food intake (11 (SE 1.5) g/d) rats depleted on diet $\mathrm{HP}+\mathrm{C}$ consumed over twice as much supplemental carnitine during the repletion period, an average of $48 \mathrm{mmol}$.

\section{Liver and plasma carnitine}

Protein-deficient rats developed a slight but non-significant deficit in liver carnitine concentration relative to controls (Table 2), and repletion with the HP diet was associated with a significant deficit in liver carnitine concentration (Table 3). Even after 5 weeks of repletion, rats treated with adequate protein were unable to recover control concentrations of liver carnitine. Growth of the liver, however, meant that these rats were able to increase the amount of carnitine per liver from 867 (SE 152) nmol/liver at the end of the depletion period to 2075 (SE 253) nmol/liver 1 week after beginning the repletion diet (values not shown).

Rats fed on the $\mathrm{HP}+\mathrm{C}$ repletion diet, on the other hand, showed a marked increase in liver carnitine concentration by 1 week repletion, and this value remained as high as control values after 5 weeks of $\mathrm{HP}+\mathrm{C}$ feeding (Table 3). For rats fed on the $\mathrm{LP}+\mathrm{C}$ repletion diet, liver carnitine concentration was higher than that of controls after 5 weeks of carnitine supplementation.

Protein-depleted rats developed a significant deficit in plasma carnitine relative to controls, and this level remained low on the HP repletion diet. In both carnitinesupplemented groups, $\mathrm{HP}+\mathrm{C}$ and $\mathrm{LP}+\mathrm{C}$, plasma carnitine rose dramatically after 1 week of supplementation, but fell after 5 weeks of supplementation. For the HP $+\mathrm{C}$ group, 5 weeks of supplemental carnitine was associated with plasma carnitine levels higher than 
Table 2. Liver weight, liver lipid and carnitine concentration, and plasmu carnitine of proteindepleted and control rats during the depletion period

(Mean values with their standard errors)

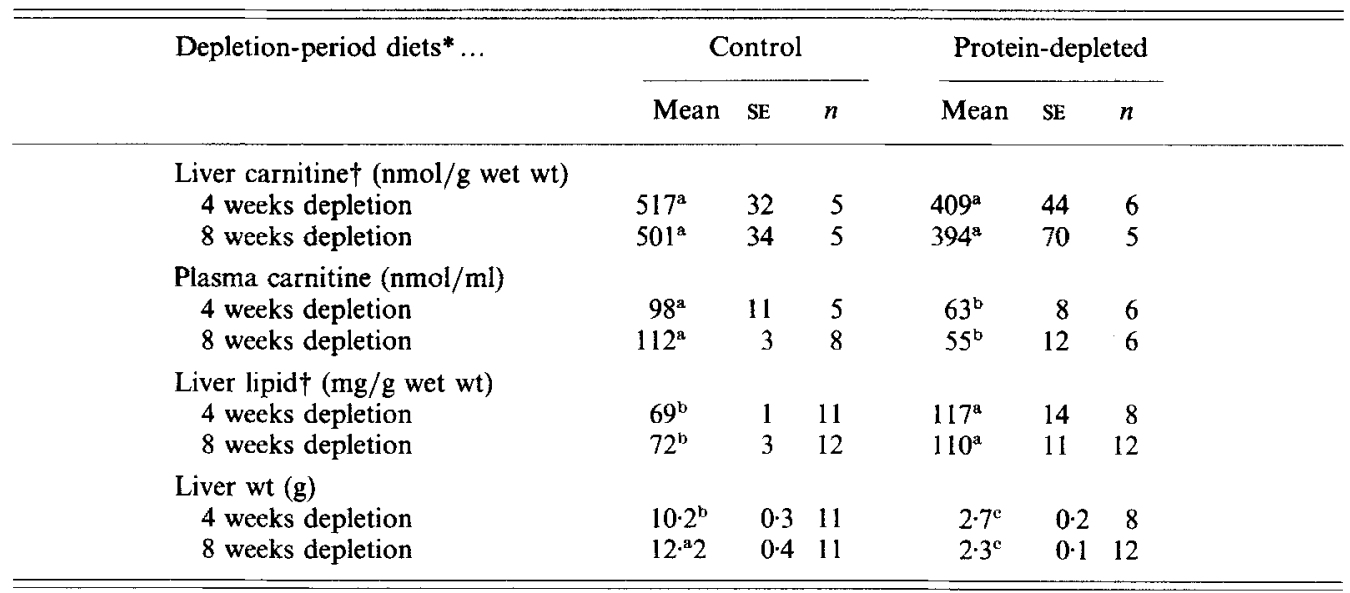

a,b,c Means within a measure with the same superscript letter were not significantly different (StudentNewman-Keuls test; $P<0 \cdot 05$ ).

* Depletion-period diets: control (stock open-formula cereal-based diet), and protein-depleted ( $5 \mathrm{~g}$ lactalbumin $/ \mathrm{kg}$ ); for details of diets, see Table 1 and p. 210 .

$\dagger$ Analysis of variance for liver carnitine concentration and liver lipid concentration was performed on logtransformed values.

those of HP-repleted rats and equivalent to controls. While plasma carnitine concentration showed a significant positive correlation $(r 0.65, P<0.05)$ with liver weight, liver carnitine concentration showed a non-significant negative correlation $(r-0 \cdot 11)$ with liver weight.

\section{Liver lipid}

Protein-depleted rats had high liver lipid concentrations, extending from a minimum (74 $\mathrm{mg} / \mathrm{g}$ wet weight) within the range of control rats to a maximum $(200 \mathrm{mg} / \mathrm{g}$ wet weight $)$ nearly three times the control mean. Rats repleted with diets $\mathrm{HP}$ or $\mathrm{HP}+\mathrm{C}$ showed a rapid reduction in liver lipid concentration to levels equivalent to those of controls. Rats fed on the $\mathrm{LP}+\mathrm{C}$ repletion diet also showed a decline in lipid concentration after 1 week of supplemental carnitine, but liver lipid concentration rose after 5 weeks on the diet. Liver weights increased with protein refeeding, but did not equal control levels after 5 weeks of refeeding (Table 3 ).

\section{Tolerance tests}

Both BATT and CATT were severely depressed in protein-depleted rats (Tables 4 and 5). BATT, for example, was close to $90 \%$ in control rats throughout the study. For proteindepleted rats, BATT averaged only about two-thirds that amount during the depletion period (Table 4) and this value continued to decline during repletion in the $\mathrm{LP}+\mathrm{C}$ group (Table 5).

Control animals in all four test-periods tolerated a cinnamic acid load essentially as well as a benzoic acid load. Generally, however, most treatment groups were slightly, though not significantly, better able to metabolize and excrete benzoic acid, with a somewhat lower percentage of a cinnamic acid test dose appearing in the urine as hippuric acid in $24 \mathrm{~h}$. Protein-depleted rats supplemented with carnitine but no added protein during the repletion period showed a reversal of the general relation between CATT and BATT; these 
Liver function tests in PEM

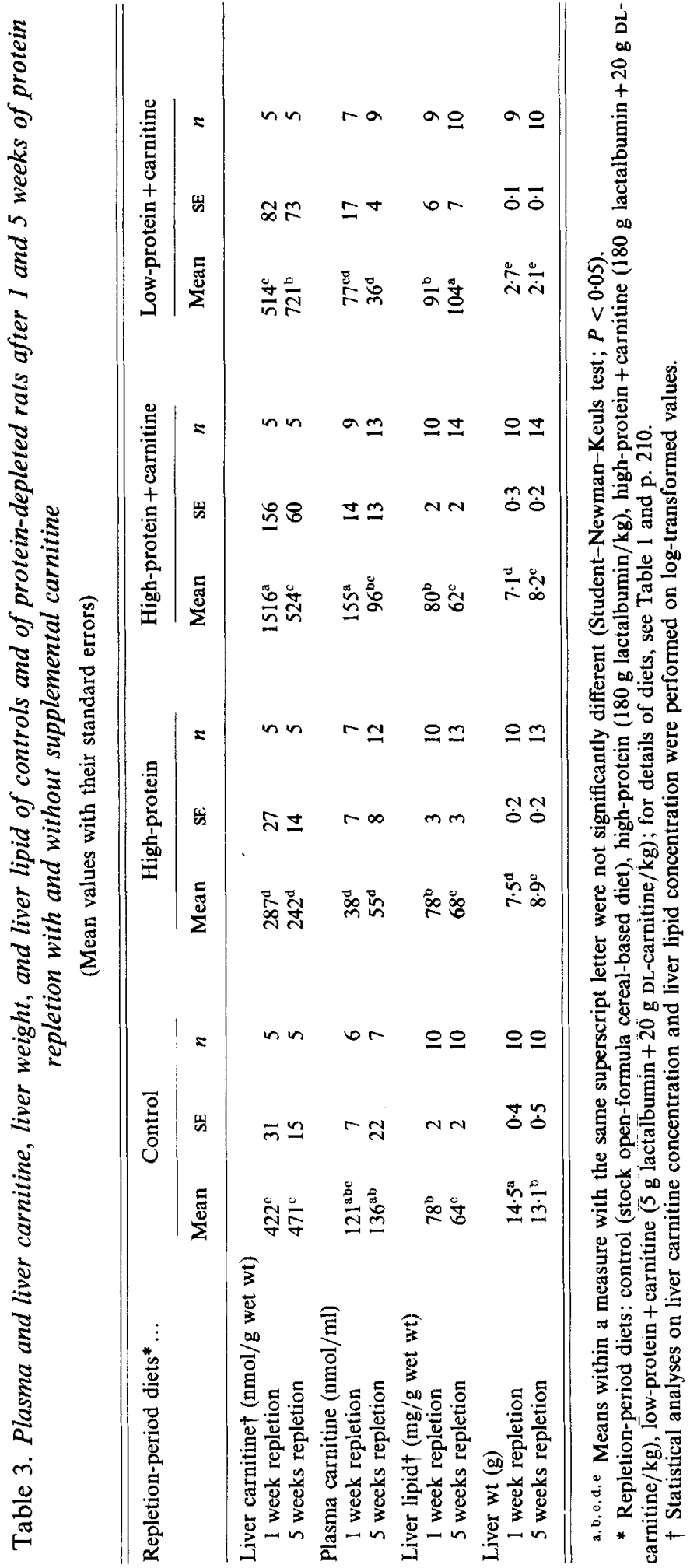


Table 4. Cinnamic acid tolerance test (CATT) and benzoic acid tolerance test (BATT) for liver function* in protein-depleted and control rats during depletion period

(Mean values with their standard errors)

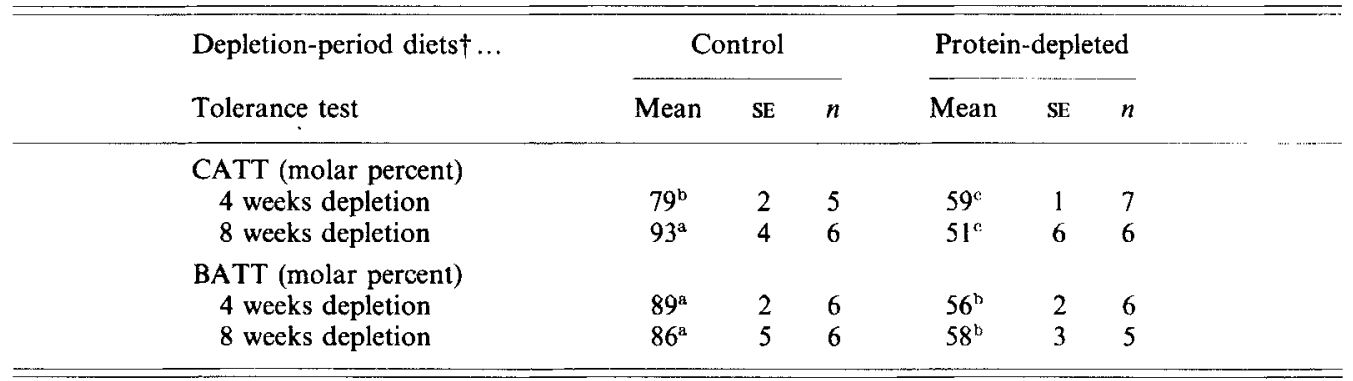

$a, b, c$ Means within a tolerance test with the same superscript letter were not significantly different (Student-Newman-Keuls test; $P<0.05$ ).

* Tolerance tests measured the molar percent of test substance (benzoic acid or cinnamic acid) excreted in the urine as hippuric acid within $24 \mathrm{~h}$ of administration.

$\dagger$ Depletion-period diets: control (stock open-formula cereal-based diet), and protein-depeleted (5g lactalbumin $/ \mathrm{kg}$ ); for details of diets, see Table 1 and p. 210 .

rats showed slightly greater tolerance to cinnamic acid than to benzoic acid at both 1 week and 5 weeks repletion (Table 5).

After just 1 week of repletion, HP- and HP $+\mathrm{C}$-fed rats performed both tolerance tests as efficiently as controls, and they maintained this level of efficiency for the remainder of the repletion period. The apparent rapid recovery in liver function by 1 week of protein repletion may be associated with a lesser challenge to the liver in these rats. Because of the rapid growth of the liver relative to body-weight, the effective dose of test substances was only 16 (SE 0.4) $\mu \mathrm{mol} / \mathrm{g}$ liver in the HP group and 17 (SE 0.8) $\mu \mathrm{mol} / \mathrm{g}$ liver in the $\mathrm{HP}+\mathrm{C}$ group at 1 week repletion, but ranged from 24 to $30(\mathrm{SE} 0.6-1 \cdot 1) \mu \mathrm{mol} / \mathrm{g}$ liver in all other groups. CATT also rose substantially with protein refeeding, but was significantly less than controls after 1 week of repletion in HP $+\mathrm{C}$-fed rats. By 5 weeks of repletion CATT had returned to control levels in both HP- and HP $+\mathrm{C}$-fed rats.

The highest positive correlation coefficients were found between liver weight and CATT or BATT (Table 6) utilizing all data-points. However, when correlations were examined by group for CATT $v$. liver weight, five groups showed statistically non-significant negative correlations. While there was no pattern to the positive or negative $r$ values explainable by the length of time or type of diet fed, this phenomenon suggests some caution in interpretation of the overall strongly positive correlation found between CATT and liver weight. The small number of animals in each group precluded further analysis of the anomaly.

Liver lipid concentration was negatively related to CATT $(r-0.62)$ (Table 6). Using multiple-regression analysis (not shown) the $R^{2}$ for CATT, including the liver weight variable, was $0 \cdot 63$, and for liver weight + liver lipid concentrations was $0 \cdot 65$. Additional variables did not further explain the variation in CATT. 


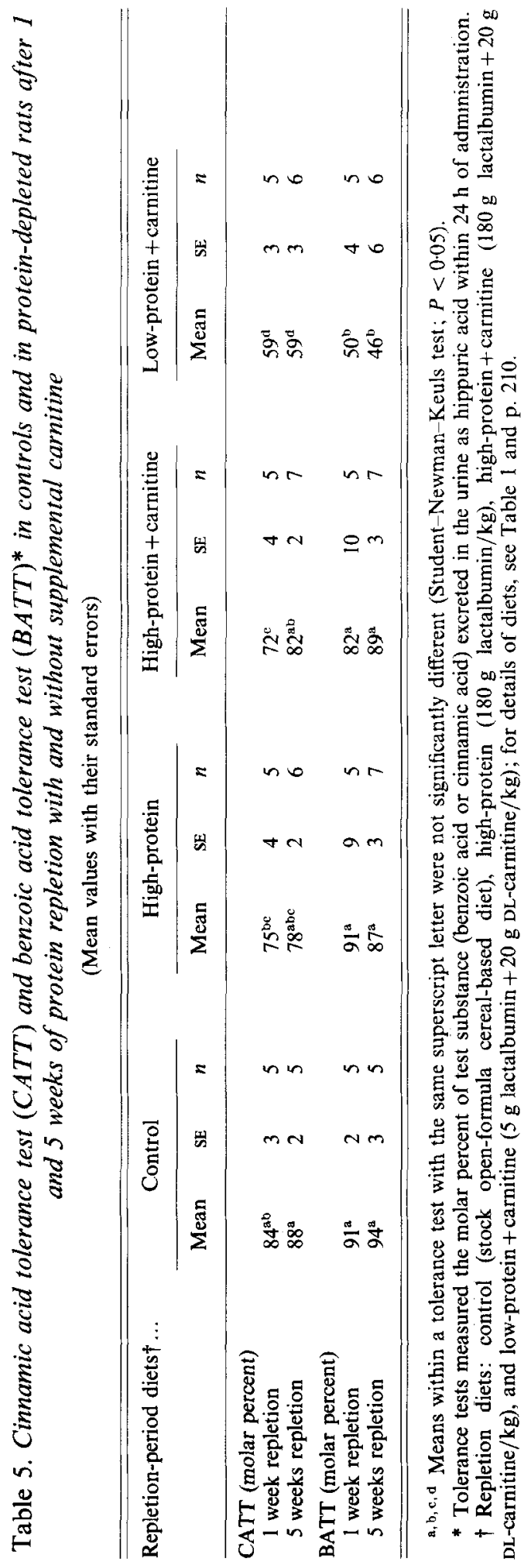


Table 6. Correlation coefficients of liver tolerance tests (cinnamic acid tolerance test $(C A T T)$ and benzoic acid tolerance test $(B A T T))$ with liver lipid and liver weight in rats

\begin{tabular}{lcccc}
\hline \hline & \multicolumn{3}{c}{ Correlation coefficients (no. of pairs in parentheses) } \\
\cline { 2 - 5 } & Liver wt & $\begin{array}{c}\text { Total lipid } \\
\text { per liver }\end{array}$ & CATT & BATT \\
\hline $\begin{array}{l}\text { Liver lipid concentration } \\
\text { (mg/g liver) }\end{array}$ & $-0.56(85)^{* * *}$ & $-0.27(85)^{* *}$ & $-0.62(42)^{* * *}$ & $-0.49(43)^{* * *}$ \\
Liver wt (g) & 1.00 & $+0.93(85)$ & $+0.79(42)^{* * *}$ & $+0 \cdot 72(42)^{* * *}$ \\
Total lipid/liver (mg) & 1.00 & $+0.67(42)^{* * *}$ & $+0.64(42)$ \\
CATT (\%) & & 1.00 & $\dagger$ \\
BATT (\%) & & & 1.00
\end{tabular}

** $P<0.01, * * * P<0.001$.

$\dagger$ CATT and BATT were tested on different animals within a group, thus no coefficients can be determined.

\section{DISCUSSION \\ Liver function tests}

The cause and treatment of the fatty liver of PEM are poorly understood. Usual treatment protocols may actually increase liver lipid (McLaren et al. 1968). Decreased lipoprotein synthesis for lipid mobilization or increased hepatic triglyceride synthesis probably contribute to the fatty liver of PEM (Truswell, 1975; Portman et al. 1981), but limited oxidation of liver lipid due to carnitine deficiency may also play a part.

Deficiency of carnitine lowers the activity of carnitine acyltransferase, an enzyme essential for fatty acid oxidation in mitochondria, resulting in accumulation of lipid within cells (McGarry \& Foster, 1980). Carnitine is ordinarily biosynthesized from lysine and methionine, but the inadequate diets that produce kwashiorkor are likely to be limited both in the amino acid precursors for carnitine (Broquist \& Borum, 1981) and in preformed carnitine itself (Mitchell, 1978). Low plasma carnitine levels have been observed in children and adults on protein-deficient diets (Khan \& Bamji, 1977; Tanphaichitr et al. 1980).

Clinical research efforts to improve understanding of the liver pathology of PEM are hampered by the absence of liver function tests appropriate for children with PEM. Many of the standard liver function tests distinguish only advanced stages of liver damage, including necrosis and cirrhosis, not normally seen with PEM (Srikantia et al. 1964; Tobiasson \& Boeryd, 1980). Other liver function tests assess blood flow through the liver, or patency of the biliary tree rather than impaired parenchymal cell function (Royle $e t$ al. 1978; Gitnick, 1981). Alternative tests for assessing liver function (for example, serum transport protein measurements) reflect an acute response to protein deprivation rather than functional impairment associated with parenchymal cell damage (Golden, 1982). These tests are particularly inappropriate for children with PEM.

Alternative proposals to measure liver function in PEM need to be evaluated. Use of indocyanin green uptake to assess liver impairment in protein-deprived rats was reported to be specific and sensitive (Jahoor \& Jackson, 1982). A similar effort was made in the present study to assess BATT and CATT for correlation with liver lipid concentration and with liver weight in rats at different stages of protein depletion and repletion.

Benzoic acid is detoxified in the liver by conjugation with glycine to form hippuric acid. This two-stage biochemical process takes place on the inner membrane of the 
coenzyme A (catalysed by butyrate-CoA ligase (benzoyl CoA synthetase; EC 6.2.1.2)) and a conjugation step whereby the benzoyl $\mathrm{CoA}$ is transferred to glycine to form hippurate catalysed by glycine acyltransferase $(E C 2.3 .1 .13)$. Hippuric acid is then eliminated by the kidney (Schnacter \& Taggart, 1954; Gatley \& Sherratt, 1977).

In the 1930s, Quick (1933) noted that this synthesis is dependent on two functions of the healthy liver: its ability to conjugate benzoic acid with glycine and its ability to furnish glycine, a non-essential amino acid. Quick (1933) determined that, on exposure to oral benzoic acid, patients with several types of liver disease excreted reduced amounts of hippuric acid compared with normal controls, and proposed a test for liver function using this determination.

The original method used a gravimetric analysis for determining hippuric acid in urine. This problematical analysis hampered routine use of Quick's (1933) test for liver function. A faster and more sensitive thin-layer chromatography method can now replace the gravimetric analysis (Teuchy \& Van Sumere, 1969; Van Sumere et al. 1969), making Quick's (1933) test a more useful tool for clinical diagnosis.

Benzoic acid appears to be safely used to test liver function. It is present naturally in foods, especially berries and fruit, and is approved by the Food and Drug Administration in the United States for use as a preservative by the food industry. In the present study, control rats excreted high percentages of the benzoic acid dose within $24 \mathrm{~h}$ following its administration. Protein-deficient rats excreted much lower percentages. The assumptions made for the standard reading of the test results attribute this to poor conjugating ability of the liver parenchymal cells, since adequate glycine was supplied with the benzoic acid dose. It should be noted that the test was not specific for fatty liver: BATT correlated as well with liver weight as with liver lipid concentration.

CATT is similar in principle to BATT. The normal liver, through $\beta$-oxidation, converts cinnamic acid to benzoic acid, which is then handled just as exogenous benzoic acid is handled: it is conjugated with glycine for excretion as hippuric acid (Fig. 1). Again, abnormal hepatic function is reflected in decreased excretion of hippuric acid. Unlike BATT, this test has not yet been used clinically, but has been suggested as a liver function test based on its direct relation with liver lipid metabolism (Zimmerman, 1974).

Both the present study and previous work with healthy rats has shown that cinnamic acid is essentially as good a precursor for urinary hippuric acid as benzoic acid, with $\beta$-oxidation of cinnamic acid occurring efficiently in normal hepatocytes (Teuchy \& Van Sumere, 1971).

Several problems might be anticipated with use of BATT and CATT in detecting compromised liver function in PEM: the first is malnutrition-induced intestinal malabsorption of an orally administered dose. Varying degrees of malabsorption could make the tests difficult to standardize from one patient to another. The present study used intraperitoneal delivery of cinnamic acid and benzoic acid. Route of administration of test substances to human beings where malabsorption may exist needs to be determined experimentally. A second anticipated problem is that altered nitrogen economy might change the availability of glycine for the conjugation process (Beliveau \& Brusilow, 1987). In the present study, glycine was provided with the test substances in equimolar amounts in order to eliminate this complication. Excess glycine appears to be readily catabolized in rat liver (Petzke et al. 1986). DeVries \& Alexander (1948) described such a modification of Quick's (1933) original test in an attempt to focus on the liver's conjugating ability rather than its amino acid synthesizing ability. A final caution in interpretation of these liver function tests in PEM is that blood flow through the liver and kidney may be abnormal, and thus alter hepatic uptake of the test compound or excretion of hippuric acid. Although impaired blood flow owing to cirrhosis is not a problem in the liver disease of PEM, cardiac 
Cinnamic acid

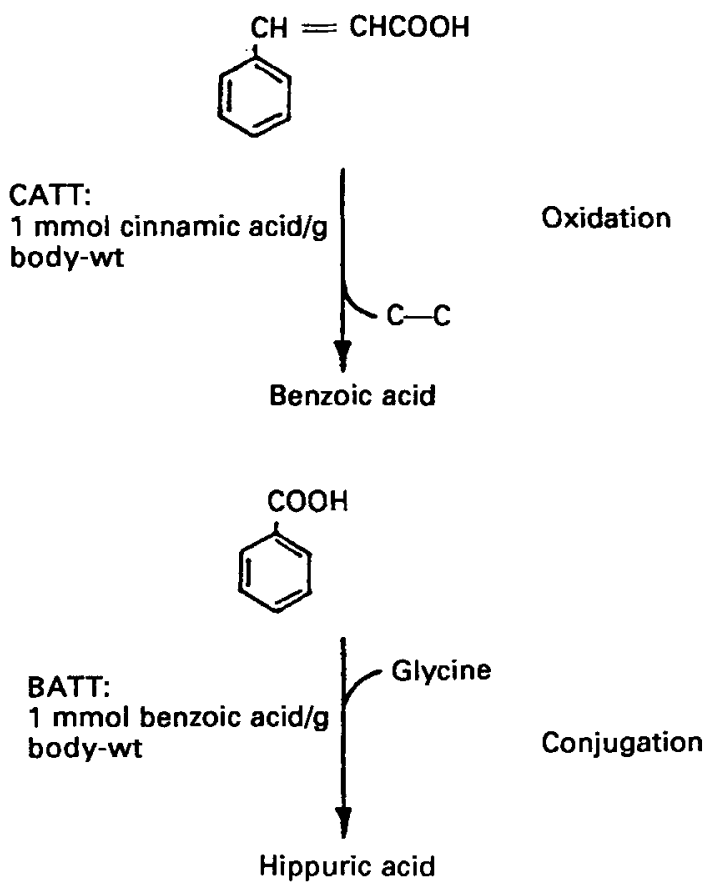

Measure excretion in urine for $24 \mathrm{~h}$ after test load is administered

Fig. 1. Metabolic basis for the benzoic acid tolerance test (BATT) and the cinnamic acid tolerance test (CATT).

output is often reduced, lowering flow-rate through both the liver and the renal glomeruli (Royle et al. 1978).

These considerations were not addressed by Quick (1933) in his original papers on use of this liver function test, but should not be ignored in attempts to explain the differences among experimental groups in the present study. Depressed cardiac output or glomerular filtration rate, rather than hepatic cell disruption, may be responsible for at least part of the depressed hippuric acid excretion observed in this rat model of protein deficiency.

\section{Effect of carnitine supplementation}

While carnitine deficiency has not been reported in normal human beings on adequate diets, low plasma carnitine levels are observed in several pathological conditions, including PEM (Khan \& Bamji, 1977; Tanphaichitr et al. 1980). Previous work in rats has shown protein deficiency to be associated with a tissue redistribution of carnitine: liver levels rise as plasma levels fall (Khan \& Bamji, 1979). It is unclear whether the inverse relation between liver and plasma carnitine concentrations is an adaptive response to the proteindeficient status of the animals or is a maladaptive inability to maintain homeostatic conditions in the absence of adequate protein nutrition.

In the present study, plasma carnitine fell during protein depletion to levels below the control levels, while liver carnitine concentration remained as high as control levels. While plasma carnitine concentration showed a significant positive correlation with liver weight, 
liver carnitine concentration showed a slight, though non-significant, negative correlation with liver weight, indicating that liver carnitine concentration tended to rise slightly with declining protein status. This raises the possibility that contraction in liver size rather than redistribution of carnitine could explain the retention of liver carnitine concentration in the face of reduced plasma carnitine in protein-depleted rats. Protein-depleted rats fed on diet HP (a high-protein diet without supplemental carnitine) showed a continued decline in liver carnitine concentration during repletion, although carnitine levels per total liver rose substantially with growth of the liver. Thus, while these animals were apparently capable of biosynthesizing carnitine, they were unable to return liver carnitine concentration to control levels even after 5 weeks of protein repletion.

Liver carnitine concentration did, however, reach control levels when carnitine was added to a high-protein repletion diet. Protein alone may not have been sufficient to allow liver carnitine synthesis to proceed at rates adequate to restore fully liver carnitine concentration. Liver carnitine concentration was substantially higher at 1 week repletion than at 5 weeks repletion, however, in carnitine-supplemented rats.

This fall in liver carnitine concentration over time with continued carnitine supplementation may be associated with feeding supplemental DL-carnitine rather than the Lisomer. D-cartinine has been shown to displace $\mathrm{L}$-carnitine in rat heart and skeletal muscle (though not in liver) (Paulson \& Shug, 1981; Rebouche, 1983). A racemic mixture, however, did raise tissue L-carnitine above control levels (Rebouche, 1983), and whether Dcarnitine contributed to the decline in liver L-carnitine observed after 5 weeks of DLcarnitine feeding in the present study is unclear.

Rats fed on LP $+\mathrm{C}$ (a low-protein repletion diet supplemented with carnitine) accumulated liver carnitine more slowly than carnitine-supplemented protein-repleted rats, and reached a higher concentration by 5 weeks than at 1 week repletion. Assimilation of carnitine into the livers of protein-deprived animals appears to be poor; both intestinal absorption and uptake from blood to hepatocyte may be depressed, since cellular membrane transport of carnitine is a protein-dependent process (York et al. 1983).

Although carnitine has been shown to reduce lipid infiltration in certain pathological conditions (Sengers et al. 1980), carnitine alone did not significantly enhance liver recovery from fat infiltration in protein-depleted rats. Although it did promote a modest temporary decline, liver lipid concentration remained well above control levels at the end of the study (Table 3). Liver function as measured by BATT and CATT did not improve but continued to decline in the $\mathrm{LP}+\mathrm{C}$ group, probably because the rats were exposed to an additional period of protein deprivation.

Additional protein, however, was associated with a rapid reduction in the high lipid concentration induced by the protein-deficient diet. Liver fat concentration returned to control levels within 1 week of initiating the high-protein repletion diet. No advantage in reducing liver lipid concentration was observed when carnitine was added to the protein supplement. Carnitine plus protein induced a transient diarrhoea which may have accounted for the modestly delayed recovery of the liver on this regimen. The diarrhoea had resolved after 2 weeks.

The effects of treatments on removing fat $v$. lowering fat concentration in liver cells due to growth of the liver are difficult to separate in the present study. The rapid expansion of liver size when protein was re-introduced could explain the entire reduction in liver lipid concentration to control levels. Mean increase in liver weight was $226 \%$ after 1 week on a high-protein diet, while the mean decrease in liver lipid concentration was only $29 \%$. Only a modest increase in liver weight, however, was observed when carnitine alone was added to the depletion diet, yet lipid concentration fell temporarily to a level equivalent to controls. This reduction may be an effect of supplemental carnitine on lipid oxidation. 
The rat model for PEM used in the present study provided only specific, limited information on the effects of carnitine supplementation on fatty liver and on the sensitivity and specificity of the tolerance tests for liver function. Much further work remains in evaluating these aspects in human subjects.

This research was supported in part by Washington State Agriculture Research Center project no. 0394 and in part by the Thrasher Research Fund (Project 6475). The authors wish to thank the Thrasher Research Fund for grant support, and to acknowledge the contributions of Dr Linda K. Massey to this research.

\section{REFERENCES}

Anthony, L. E. \& Edozien, J. C. (1975). Experimental protein and energy deficiencies in the rat. Journal of Nutrition 105, 631-648.

Beliveau, G. P. \& Brusilow, S. W. (1987). Glycine availability limits maximum hippurate synthesis in growing rats. Journal of Nutrition 117, 36-41.

Broquist, H. P. \& Borum, P. R. (1981). Carnitine biosynthesis. Nutritional implications. Nutrition Research 4, 181-204.

DeVries, A. \& Alexander, B. (1948). Studies on amino acid metabolism. III. Plasma glycine following the ingestion of benzoate. Journal of Clinical Investigation 27, 665-671.

Edozien, J. C. (1968). Experimental kwashiorkor and marasmus. Nature 220, 917-919.

Edozien, J.C. \& Switzer, B. R. (1978). Fatty liver in experimental protein-energy malnutrition in the rat. Experimental Molecular Pathology 29, 1-11.

Garrow, J. S. \& Pike, M. C. (1967). The short-term prognosis of severe primary infantile malnutrition. British Journal of Nutrition 21, 155-165.

Gatley, J.S. \& Sherratt, H.S. (1977). The synthesis of hippurate from benzoate and glycine by rat liver mitochondria. Submitochondrial localization and kinetics. Biochemical Journal 166, 39-45.

Gitnick, G. (1981). Assessment of liver function. Surgical Clinics of North America 61, 197-207.

Golden, M. H. N. (1982). Transport proteins as indices of protein status. American Journal of Clinical Nutrition 35, $1159-1165$.

Harding, R. S., Leveille, G. A. \& Barker, E. M. (1967). Biochemical Procedures, vol. 1, pp. 23-24. Colorado: US Army Medical Research and Nutrition Laboratory, Fitzsimmons General Hospital.

Jahoor, F. \& Jackson, A. A. (1982). Hepatic function in rats with dietary induced fatty liver, as measured by the uptake indocyanin green. British Journal of Nutrition 47, 391-397.

Khan, L. \& Bamji, M. S. (1977). Plasma carnitine levels in children with protein-calorie malnutrition before and after rehabilitation. Clinica Chimica Acta 75, 163-166.

Khan, L. \& Bamji, M.S. (1979). Tissue carnitine deficiency due to dietary lysine deficiency: triglyceride accumulation and concomitant impairment in fatty acid oxidation. Journal of Nutrition 109, 24-31.

McGarry, J. D. \& Foster, D. W. (1976). An improved and simplified radioisotopic assay for the determination of free and esterified carnitine. Journal of Lipid Research 17, 277-282.

McGarry, J. D. \& Foster, D. W. (1980). Systemic carnitine deficiency. New England Journal of Medicine 303, 1413-1415.

McLaren, D. S., Faris, R. \& Zekian, B. (1968). The liver during recovery from protein-calorie malnutrition. Journal of Tropical Medicine and Hygiene 71, 271-281.

McLean, A. E. M. (1962). Hepatic failure in malnutrition. Lancet ii, 1292-1297.

Mitchell, M. E. (1978). Carnitine metabolism in human subjects. I. Normal metabolism. American Journal of Clinical Nutrition 31, 293-306.

Pace, J. A., Wannemacher, R. W. \& Neufeld, H. A. (1978). Improved radiochemical assay for carnitine and its derivatives in plasma and tissue extracts. Clinical Chemistry 24, 32-35.

Paulson, D. J. \& Shug, A. L. (1981). Tissue specific depletion of L-carnitine in rat heart and skeletal muscle by Dcarnitine. Life Sciences 28, 2931-2938.

Petzke, M. J., Albrecht, V. \& Przybilski, M. (1986). The influence of high glycine diets on the activity of glycinecatabolizing enzymes and on glycine catabolism in rats. Journal of Nutrition 116, 742-750.

Portman, O. W., Alexander, M. \& Neuringer, M. (1981). Effects of long-term protein deficiency on plasma lipoprotein concentrations and metabolism in rhesus monkeys. Journal of Nutrition 111, 733-745.

Quick, A. J. (1933). The synthesis of hippuric acid: a new test of liver function. American Journal of Medical Science 185, 630-637.

Rebouche, C. (1983). Effect of dietary carnitine isomers and butyrobetaine on L-carnitine biosynthesis and metabolism in the rat. Journal of Nutrition 113, 1906-1913.

Royle, G., Kettlewell, M. G. W. \& Illic, V. (1978). Galactose and hepatic metabolism in malnutrition and sepsis in man. Clinical Science and Molecular Medicine 55, 199-204. 
Schnacter, D. \& Taggart, J. V. (1954). Glycine $N$-acylase: purification and properties. Journal of Biological Chemistry 208, 263-268.

Sengers, A., Bakkeren, J. A., \& Trijbels, J. M. F. (1980). Successful carnitine treatment of non-carnitine-deficient lipid storage myopathy. Pediatrics 135, 205-209.

Srikantia, S. G., Jacob, C. M. \& Reddy, V. (1964). Serum enzyme levels in protein-calorie malnutrition studies in children with kwashiorkor and marasmus. American Journal of Diseases of Childhood 107, 256-261.

Steel, R. G. D. \& Torrie, J. H. (1975). Principles and Procedures of Statistics. New York: McGraw-Hill.

Tanphaichitr, V., Lerdvuthisopon, N. \& Dhanamitta, S. (1980). Carnitine status in Thai adults. American Journal of Clinical Nutrition 33, 876-882.

Teuchy, H. \& Van Sumere, C. F. (1969). Quantitative thin layer chromatographic determination of hippuric acid in rat urine. Clinica Chimica Acta 25, 79-84.

Teuchy, H. \& Van Sumere, C. F. (1971). The metabolism of $\left(1-{ }^{14} \mathrm{C}\right)$-phenylalanine, $\left(3^{-14} \mathrm{C}\right)$-cinnamic acid and $(2-$ $\left.{ }^{14} \mathrm{C}\right)$-ferrulic acid in the rat. Archives Internationales de Physiologie et de Biochimie 71, 589-595.

Tobiasson, P. \& Boeryd, B. (1980). Serum cholic and chenodeoxycholic acid conjugates and standard liver function tests in various morphological stages of alcoholic liver disease. Scandinavian Journal of Gastroenterology 15, 657-663.

Truswell, A.S. (1975). Carbohydrate and lipid metabolism in protein-calorie malnutrition. In Protein-Calorie Malnutrition, pp. 119-141 [M. Winick, editor]. New York: Academic Press.

Van Sumere, C. F., Teuchy, H. \& Pe, H. (1969). Quantitative investigation on the hippuric acid formed in healthy and diseased individuals. Clinica Chimica Acta 25, 85-91.

Waterlow, J. C. (1975). Amount and rate of disappearance of liver fat in malnourished infants in Jamaica. American Journal of Clinical Nutrition 28, 1330-1336.

Wateriow, J. C., Cravioto, J. \& Stephen, J. M. L. (1960). Protein malnutrition in man. Advances in Protein Chemistry 15, 131-140.

Williams, C. D. (1935). Kwashiorkor: a nutritional disease of children associated with a maize diet. Lancet ii, 1151-1153.

York, C. M., Cantrell, C. R. \& Borum, P. R. (1983). Cardiac carnitine deficiency and altered carnitine transport in cardiomyopathic hamsters. Archives of Biochemistry and Biophysics 221, 526-533.

Zimmerman, H. J. (1974). Tests of hepatic function. In Todd-Sanford Clinical Diagnosis by Laboratory Methods, p. 677 [I. Davidsohn and B. Henry, editors]. Philadelphia: W. B. Saunders. 